\title{
Equatorial enhancement of Pc5-6 magnetic storm time geomagnetic pulsations
}

\author{
B. M. Pathan ${ }^{1}$, N. G. Kleimenova ${ }^{2}$, O. V. Kozyreva ${ }^{2}$, D. R. K. Rao ${ }^{1}$, and R. L. Asinkar ${ }^{1}$ \\ ${ }^{1}$ Indian Institute of Geomagnetism, Colaba, Mumbai 400 005, India \\ ${ }^{2}$ Institute of Physics of Earth, 123810, Russia
}

(Received December 21, 1998; Revised July 8, 1999; Accepted August 2, 1999)

\begin{abstract}
Geomagnetic Pc5-6 (1-4 mHz) pulsations during three magnetic storms have been analyzed using ground observations at an array of 5 Indian stations ranging from $0.8^{\circ}$ to $25^{\circ}$ dip latitudes and two pairs of low-latitudes $\left(\sim 20^{\circ}\right)$-near equator $\left(\sim 4-5^{\circ}\right)$ stations, located at $\sim 4$ hours to the West and East from this meridian. The pulsations are found to occur as individual wave packets that are characterized by similar spectra at all stations with two dominate bands of frequencies: $\sim 1.5-2.0 \mathrm{mHz}$ and $\sim 2.5-4.0 \mathrm{mHz}$. Very strong daytime equatorial enhancement of the wave intensity has been noted. The higher enhancement is observed near noon while it is reduced towards the morning and evening sectors. The polarization of both frequency bands at the equator is found to be almost linear, mainly along the $H$-direction. It has been found that the amplitude of the $D$-component decreased with decrease in the latitude towards the equator. One of the spectral peaks is observed exclusively at the dip equator station and it has been attributed to the generation/amplification of MHD waves by the equatorial electrojet instabilities.

The mechanism of day time equatorial enhancement of long period geomagnetic pulsations and the propagation characteristics are discussed.
\end{abstract}

\section{Introduction}

Many researchers have reported on the ground-based observations of large amplitude and long period ( $\sim 1-6 \mathrm{mHz}$ ) day time Pc5-6 geomagnetic pulsations typical at high and polar latitudes (e.g. Walker et al., 1992; Dunlop et al., 1994; Ziesolleck and McDiarmid, 1994; Bolshakova et al., 1995; McHarg et al., 1995). The mechanism of their generation apparently corresponds to field line resonances driven by magnetosphere cavity or waveguide modes (Harrold and Samson, 1992; Samson et al., 1992).

However, the geomagnetic Pc5-6 range variations are also observed at low latitudes (Lilley and Bennett, 1973). The spatial structure of mid and low-latitudes $\left(\sim 21-48^{\circ}\right.$ geomag. lat.) Pc5 has been discussed by Ziesolleck and Chamalaun (1993). These authors have found a sharp decrease of the pure state total power spectra pulsations with latitude and increasing probability of low latitude Pc5 occurrence with magnetic activity. The development of strong magnetic storms leads to significant large-scale structural changes of the magnetosphere, and, thus, the properties of geomagnetic pulsations observed on the ground are expected to change significantly.

The unusual globally coherent Pc5 geomagnetic event during one of the greatest magnetic storms on March 24, 1991 has been recorded between 12-14 UT on the ground-based magnetometers at low latitudes as well as near the equator (Liu et al., 1993; Reddy et al., 1994; Trivedi et al., 1997). Enhanced amplitudes of Pc5-6 pulsations have been observed in the afternoon. Unfortunately there were no low latitude and equatorial stations located near noon, as such, the de-

Copy right(C) The Society of Geomagnetism and Earth, Planetary and Space Sciences (SGEPSS); The Seismological Society of Japan; The Volcanological Society of Japan; The Geodetic Society of Japan; The Japanese Society for Planetary Sciences. tailed characteristics of storm-time equatorial and low latitude Pc5-6 geomagnetic pulsations are not well established.

The aim of the present paper is to analyze the daytime peculiarities of storm-time Pc5-6 pulsations at low and equatorial regions using an array of 5 Indian stations from near the dip equator to low latitudes and two pairs of low latitudenear equator stations located at $\sim 4$ hours to the West and East from the array.

\section{Data}

Our investigation is based on digitized one minute sampling geomagnetic data on the latitudinal array of five Indian stations and digital INTERMAGNET data from two pairs of low latitude and near dip equator observatories. The coordinates of the stations are given in Table 1. East or west longitudinal separation of these two INTERMAGNET meridians from Indian meridian is about $4 \mathrm{hrs}$. The schematic presentation of the station locations is shown in Fig. 1. Only one station-Trivandrum (TRD) is situated near the dip equator. Three stations-Bangui (BNG), Pondicherry (PND) and Guam (GUA) are located at few degrees away from the dip equator.

One minute values of the geomagnetic $H$ and $D$ components were filtered using a zero-phase shift sixth order Butterworth type "band pass" filter for the frequency ranges 0.5-6.0 mHz (Otnes and Enochson, 1978). The amplitude spectra are computed by direct Fourier transform, amplitudes are smoothed by sliding window method over 5 points.

The long period geomagnetic pulsations during three strong magnetic storms on 21-22 February 1994, 16-18 April 1994 and 18-20 October 1995 have been selected for the study. 
Table 1. List of observatories.

\begin{tabular}{lcrrrr}
\hline & \multicolumn{2}{c}{ Geographic } & \multicolumn{2}{c}{ Geomag. (Dipole) } \\
Station name & Code & \multicolumn{1}{c}{ lat. } & Long $\left({ }^{\circ} \mathrm{E}\right)$ & \multicolumn{1}{c}{ lat. } & Long $\left({ }^{\circ} \mathrm{E}\right)$ \\
\hline Alibag & ABG & 18.63 & 72.87 & 9.74 & 145.57 \\
Bangui & BNG & 4.44 & 18.57 & 4.54 & 89.86 \\
Guam & GUA & 13.58 & 144.87 & 4.27 & 214.26 \\
Gulmarg & GUL & 34.08 & 74.40 & 24.93 & 148.85 \\
Kakioka & KAK & 36.23 & 140.19 & 26.31 & 207.26 \\
Pondicherry & PND & 11.92 & 79.92 & 2.37 & 151.69 \\
Tamanrasset & TAM & 22.79 & 5.53 & 25.07 & 80.86 \\
Trivandrum & TRD & 8.48 & 76.95 & -0.77 & 148.45 \\
Ujjain & UJJ & 23.18 & 75.78 & 13.97 & 148.84 \\
\hline
\end{tabular}

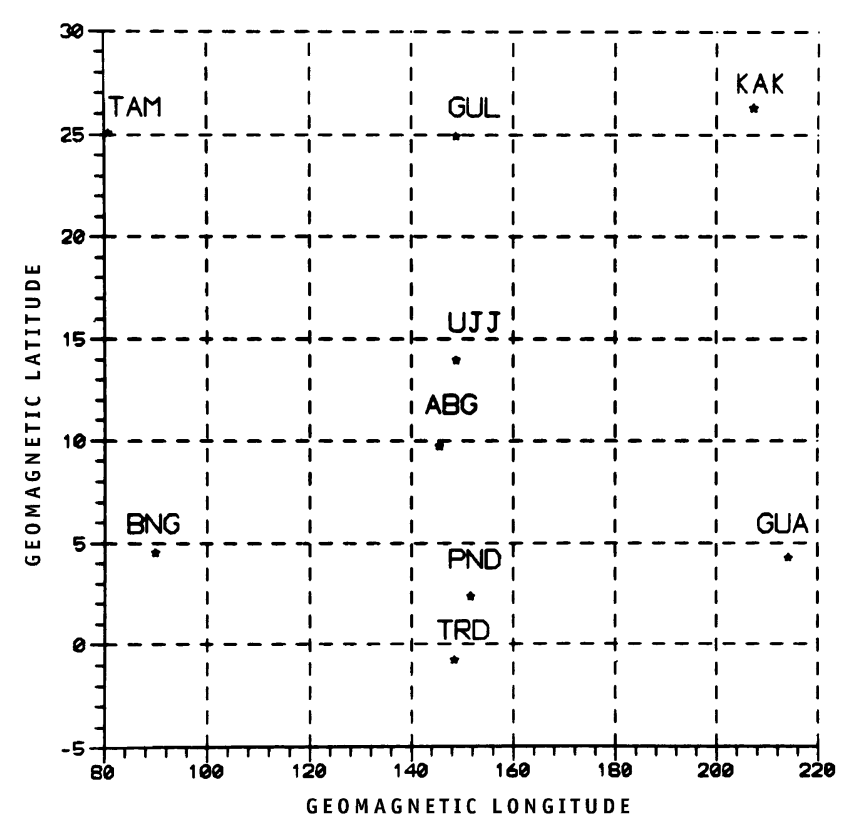

Fig. 1. Schematic map of station's location.

\section{Experimental Results}

The analyzed Pc5-6 geomagnetic pulsations at low and equatorial latitudes look like isolated simultaneous wave packets at every station.

Figure 2 shows the spectral distribution of the $H$ and $D$ components of geomagnetic pulsations in the frequency range $0.5-6.0 \mathrm{mHz}$ on February 22, 1994 for the time 0508 UT. This time corresponds to near local noon at Indian meridian, local morning at TAM-BNG and afternoon at KAK-GUA. A clearly defined and relatively broad maximum at $1.6-2.2 \mathrm{mHz}$ is present at all the stations with the largest amplitude in the $H$ component near noon. The strongest waves in the $H$-component are observed at the dip equator (TRD). At all meridian profiles, the amplitude of the $H$-component of geomagnetic pulsations increased as the dip equator is approached. This effect was stronger at noon and afternoon time than in the morning (TAM-BNG).
The 1.6-2.2 $\mathrm{mHz}$ pulsation amplitudes near the dip equator (TRD) were twice larger than at a few degrees off-equatorial station (PND).

A very narrow spectral peak, at $1 \mathrm{mHz}$, has also been observed at all the stations with pronounced amplitude at the equator. One additional spectral maximum between $\sim 2.5$ and $4.0 \mathrm{mHz}$ has seen only at the dip equator (TRD).

Similar day time equatorial enhancements of the $H$ component of Pc5-6 geomagnetic pulsations are observed at the Indian array of stations at 02-08 UT on April 17, April 18, 1994 and October 20, 1995.

In Fig. 3 are shown the $1.6-2.2 \mathrm{mHz}$ filtered pulsations at three near dip equator stations-BNG, PND and GUA on Feb. 22, 1994 in the interval 02-11 UT. The pulsations occur as individual simultaneous wave packets with similar appearance over the whole range of longitudes. The amplitude of the wave packet observed between 02 and 04 UT was the largest at GUA, (near local noon), and the amplitude of another wave packet observed between 07 UT and 08 UT was the strongest at PND (local noon). This fact demonstrates the $H$-component enhancement of the equatorial Pc5-6 pulsations intensity is confined to near local noon times.

Contrary to the properties of the $H$-component of pulsations, the behaviour of the $D$-component seems different. Firstly, in spite of the general similarity of the $H$ and $D$ component spectra, the wave intensity in the $D$ component decreases with decrease in the latitude (Fig. 2). This fact is most pronounced near noon (Indian meridian).

The same tendency (enhancement of amplitudes in $H$ and reduction in $D$ at the dip equator) has been observed on February 21, 1994 (with SSC at 09.01 UT). In the analyzed interval 09.30-12.30 UT, as in the previous events, the amplitudes of the $D$ component of geomagnetic pulsations decreased with decrease in the latitudes towards the equator. The Indian meridian was located in the afternoon sector of the Earth. The smoothed spectra of the $H$ component at four Indian stations are presented in the Fig. 4 (Alibag data were discarded because they were not of good quality at that time). There are two spectral peaks at the dip equator station Trivandrum (TRD). These are in the frequency ranges 
22 FEB $1994 \quad 5$ - 8 UT

$\mathrm{H}$
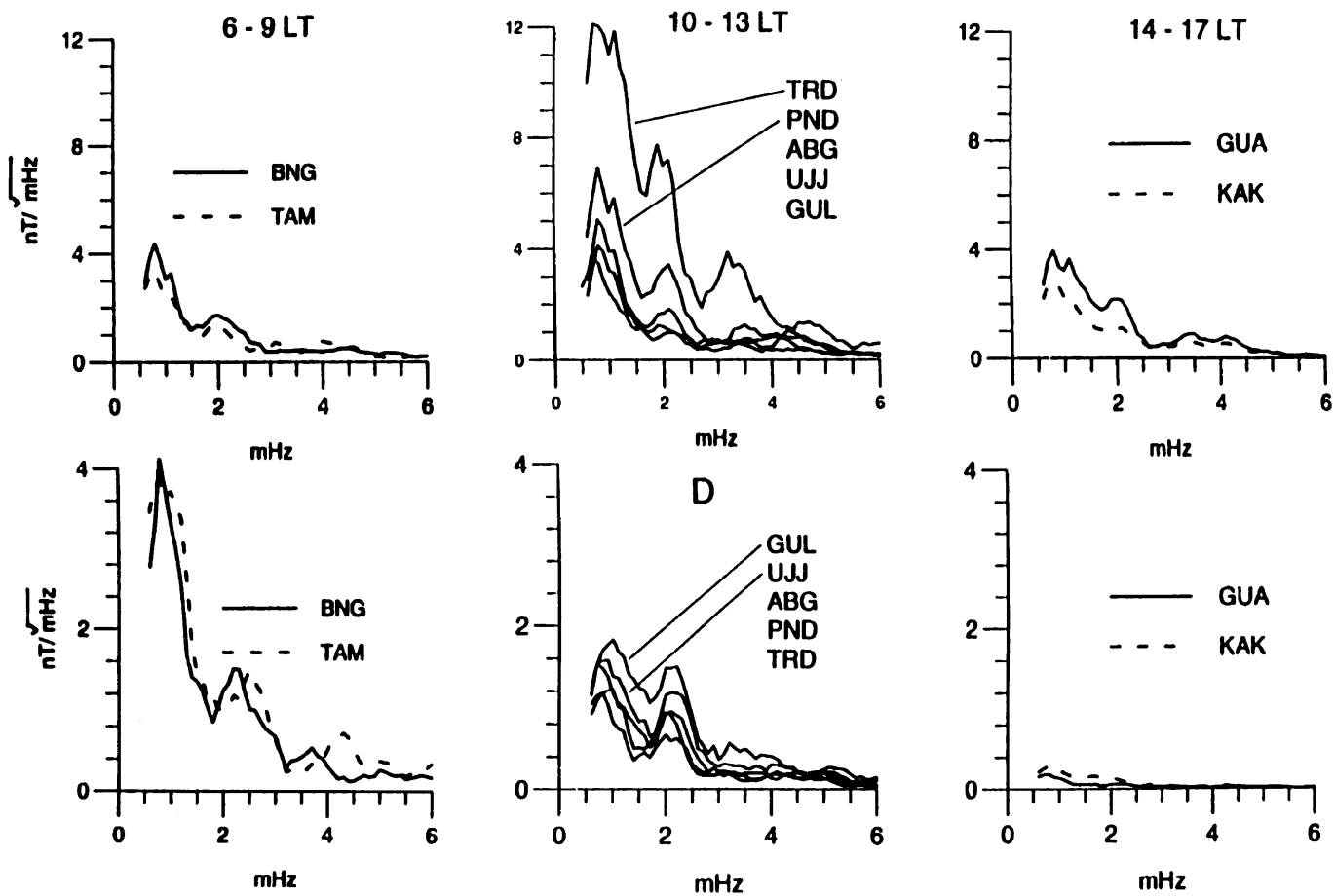

Fig. 2. Spectra of $H$ and $D$ in the frequency range $0.5-6.0 \mathrm{mHz}$ at three longitudinal sectors on February $22,1994$.

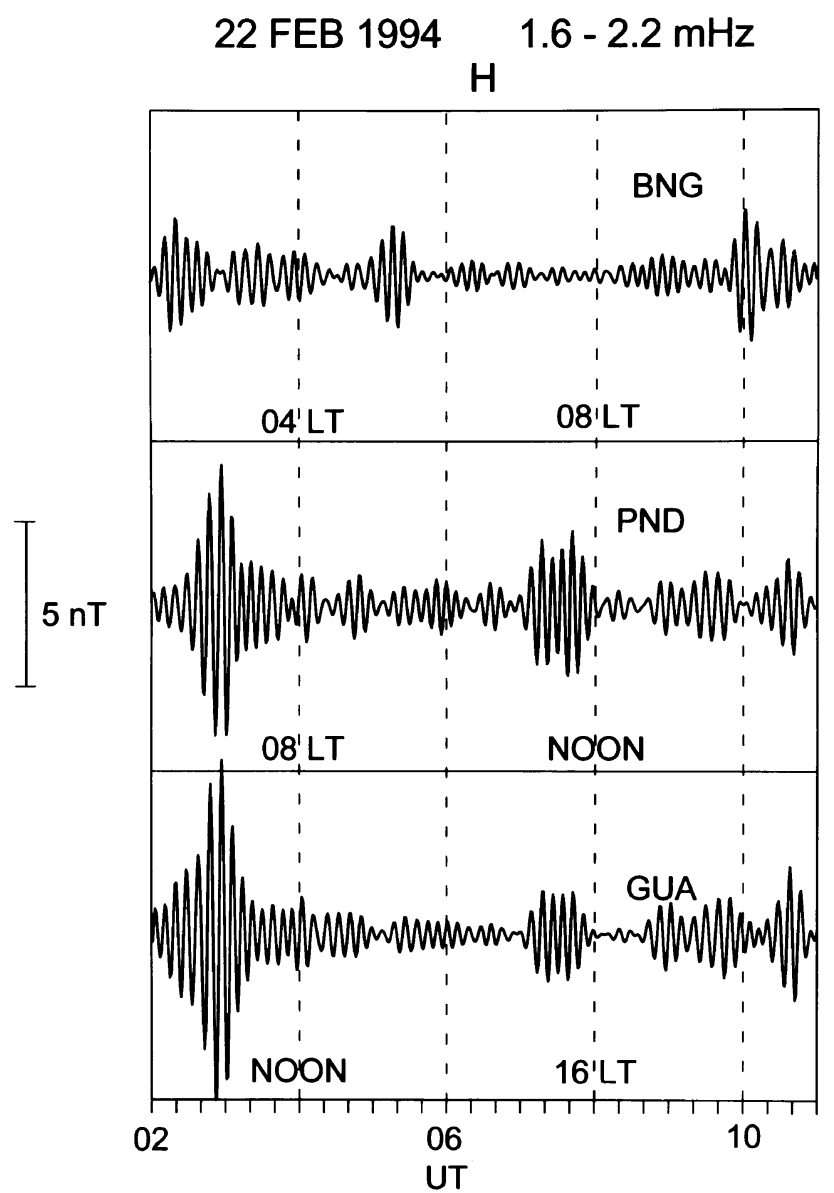

Fig. 3. Filtered pulsations (in the interval $1.6-2.2 \mathrm{mHz}$ ) at three stations, BNG, PND and GUA, "close to the dip equator", on February 22, 1994.
21 FEB 1994 09:30-12:30 UT 15-18 LT

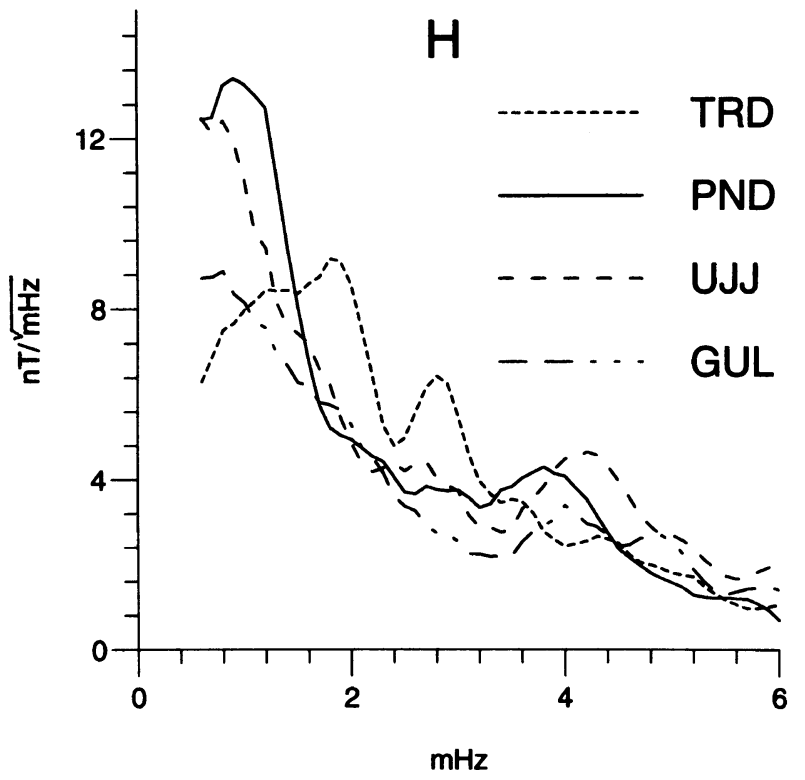

Fig. 4. Spectra of geomagnetic pulsations in $H$ between $0.5-6.0 \mathrm{mHz}$ at Indian stations on February 21, 1994.

1.6-2.2 $\mathrm{mHz}$ and $2.5-3.0 \mathrm{mHz}$ which are not distinguished as separate in the spectra at higher latitude stations. We can speculate that these waves could be generated directly by the equatorial electrojet associated instabilities. 


\section{APR $1994 \quad 18-21$ UT}

$\mathrm{H}$
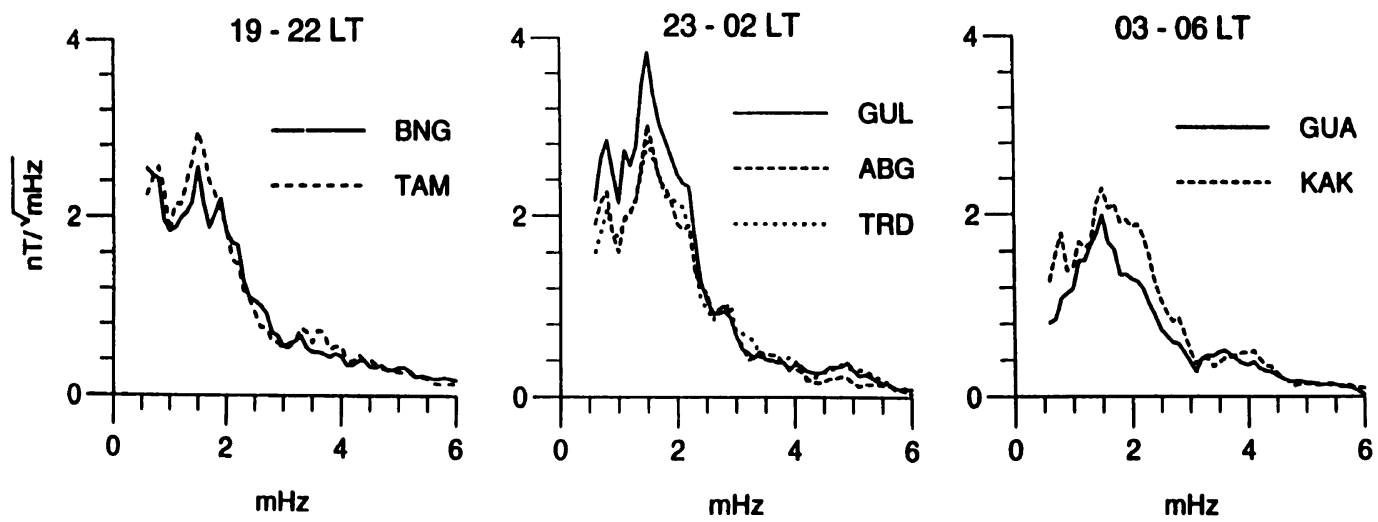

Fig. 5. Spectra of geomagnetic pulsations in $H$ between $0.5-6.0 \mathrm{mHz}$ at the three longitudinal sectors on April 17, 1994 at $18-21$ UT.

18 OCT 1995

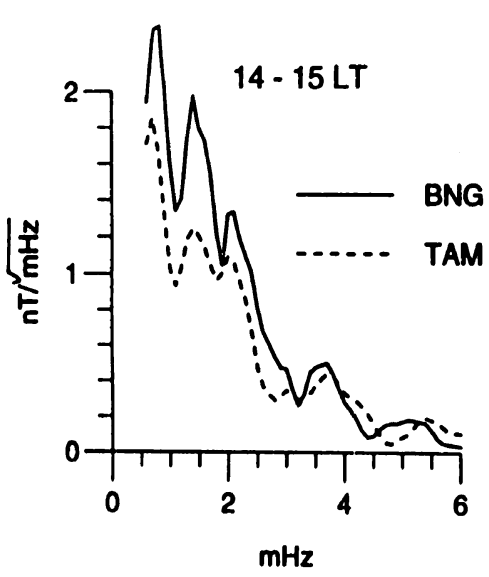

\section{$13-14$ UT}

$\mathrm{H}$
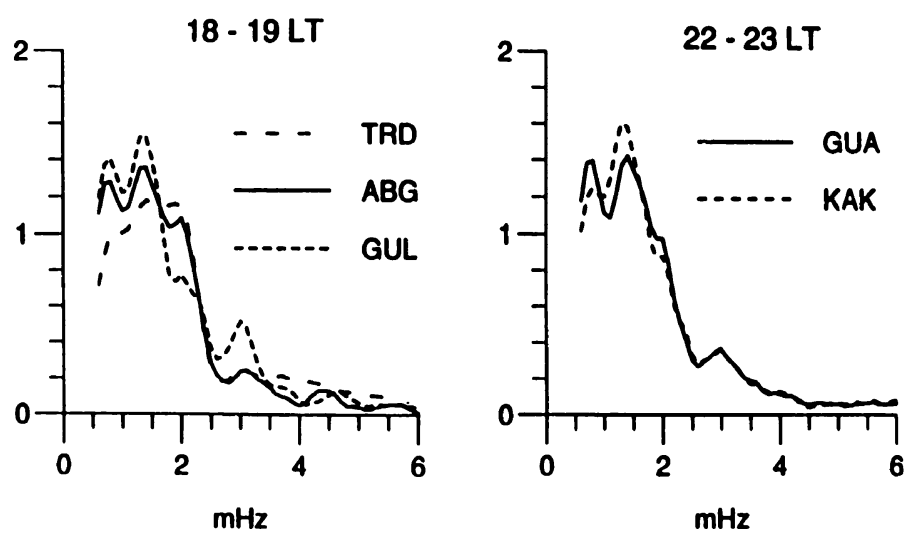

Fig. 6. Same as Fig. 5 but for October 18, 1994 at 13-14 UT.

In the night no equatorial enhancement of pulsation amplitude was observed. In Fig. 5 are shown the spectral distributions of Pc5-6 geomagnetic pulsations at three meridian stations for the event on April 17, 1994 at 18-21 UT. This time corresponds to the local evening at TAM-BNG, the midnight at GUL-ABG-TRD and the early morning at KAK-GUA. There was a common peak of power between 1 and $2 \mathrm{mHz}$ at all these stations, but contrary to daytime amplitude enhancement of $H$-component of pulsations, in the morning and evening, amplitudes show a systematic decrease with decrease in the latitude. For example, at the Indian meridian, i.e. near midnight, the intensity of $\sim 1.6$ $\mathrm{mHz}$ oscillations at dip latitude of $\sim 25^{\circ}$ (GUL) was larger than at the dip equator (TRD).

The same was observed at 13-14 UT on October 18, 1995 (Fig. 6). In the evening (Indian meridian) and near midnight (KAK-GUA) the equatorial enhancement was not observed. Only in the early afternoon at 14-15 LT (TAM-BNG) the amplitude of Pc5-6 ( $\mathrm{f}=1.0-1.7 \mathrm{mHz})$ increases toward the dip equator.

The daytime wave polarization near the dip equator was almost linear, mainly along the $H$-direction for all events analyzed. The linear polarization nearly along the magnetic meridian was observed by Kitamura et al. (1988) and Saka et al. (1988) for Pi2 and Pc3-4 pulsations at low and equatorial latitudes.

\section{Discussion and Summary}

To summarize, our results of analysis show that there is a significant enhancement of the $H$-component of stormtime Pc5-6 range $(1-4 \mathrm{mHz})$ geomagnetic pulsations at the dip equator near local noon. Similar enhancements of other classes of shorter period geomagnetic pulsations with daytime (Pi2 and Pc3-4) are clearly established from earlier studies (Jain and Srinivasacharya, 1975; Sastry et al., 1979, 1983; Saka et al., 1988; Sarma et al., 1991; Sarma and Sastry, 1995; Shinohara et al., 1998). It is also known that the equatorial electrojet can have control on other geophysical phenomena.

The equatorial electrojet is characterized by zonal ionospheric conductivity, which is very high during the daytime. In the nighttime the ionospheric conductivity is relatively reduced. Our results show that in the early morning and in the late evening as well as in the night there were no Pc5-6 amplitude enhancement in the vicinity of dip equator (Figs. 5 
and 6) in accordance with the variation in conductivity with the local time.

The equatorial daytime enhancement of geomagnetic phenomena obviously is connected with the influence of Cowling conductivity effects. But the mechanisms of that effect are not fully understood.

Various mechanisms of the superposition of the electric field to the equatorial ionosphere were considered by number of researchers. Kikuchi and Araki (1979) proposed an instantaneous transmission of polar ionospheric electric fields into the equatorial ionosphere. Kikuchi (1986) showed schematically that the westward electric field produced by the compression of the magnetosphere is transmitted to the polar ionosphere by the Alfvén wave mode and then instantaneously to the equator. The electric field decreases monotonically with decreasing latitude as has been noticed for the pulsation amplitude of the $D$-component in our study.

One of the important characteristics of geomagnetic pulsations on the ground is an azimuthal wave number $(m)$ and a phase velocity $\left(V_{\phi}\right)$. At high and middle latitudes Pc5 pulsations propagate to the East and to the West from local noon with small azimuthal wave numbers $m \sim 1-3$ (Samson $e t$ al., 1992; Harrold and Samson, 1992; Schott et al., 1998).

We have obtained the $m$-number of equatorial Pc5-6 pulsations using the digital one minute sampling interval INTERMAGNET data from two longitudinally separated pairs of stations TAM-BNG and KAK-GUA $\left(\sim 125^{\circ}\right.$ separation) (Fig. 1). At 02-06 UT, the station pair KAK-GUA is located near local noon and TAM-BNG in the early morning sector. We have computed the wave numbers, $m$, during several magnetically disturbed days for these stations with spectral peak in the frequency interval 1.6-2.2 $\mathrm{mHz}$ (Figs. 2, 5 , and 6). Unfortunately, because of limitation of 1 minute sampling, we can measure the wave phase differences between these profiles of stations with accuracy not better than one minute. We have calculated the wave number using the expression given by Olson and Rostoker (1978):

$$
m=\frac{2 \pi R \Delta \phi}{360 S} \cos \lambda
$$

where $R$ is the earth's radius, $S$ is the station separation, $\Delta \phi$ is the estimated phase difference and $\lambda$ is the latitude.

The calculated average $m$-value for waves with mean period $\sim 500 \mathrm{sec}$ between $\mathrm{BNG}$ and GUA (the geomagnetic latitude $\sim 4.4^{\circ}$ ) is $\sim 0.3-0.4$ and it is nearly the same for TAM-KAK (geomagnetic latitude $\sim 25^{\circ}$ ). Similar very low m-number has been reported by Kitamura et al. (1988) for daytime Pi2 pulsations. According to their results the azimuthal wave number for very low latitude and equatorial Pi2's was about $0.2-0.3$. This implies that Pc5-6 and daytime Pi2 waves propagate to the earth's surface in the vicinity of dip equator as compressional waves or waves with considerably strong $m=0$ component contribution.

On the other hand, at high latitudes, for instance, between Lerwick $\left(58.2^{\circ} \mathrm{N}, 82.5^{\circ} \mathrm{E}\right)$ and Sodankyla $\left(63.8^{\circ} \mathrm{N}, 107.8^{\circ} \mathrm{E}\right)$, the Pc5-6 geomagnetic pulsations with a spectral peak in the same interval of frequency $\sim 1.6-2.2 \mathrm{mHz}$ for the events discussed in this paper have been characterized by average values of azimuthal wave number $m \sim 3.0-3.5$. This suggest that the longitudinal phase velocity of Pc5-6 waves is latitude dependent, being slower at higher latitudes $(m \sim 3.5-4.0)$ and faster at lower latitudes $(m \sim 0.3-0.4)$.

The azimuthal phase velocity $\left(V_{\phi}\right)$ according to Olson and Rostoker (1978) is

$$
V_{\phi}=\frac{2 \pi f R \cos \lambda}{m} .
$$

This calculation for the mean geomagnetic latitude of BNG-GUA $\left(\sim 4.4^{\circ}\right)$ gives the apparent phase velocity $\left(V_{\phi}\right) \sim$ $200 \mathrm{~km} / \mathrm{s}$ for the waves with $m \sim 0.4$. The same value of phase velocity has been obtained by assuming the simple expression given by Herron (1966) with respect to phase wave propagation (with the knowledge of the phase front) $V_{\phi}=x / t$, where $x$ is the station separation. The apparent phase velocity between Sodankyla and Lerwick (at the geomagnetic latitude $\sim 60^{\circ}$ ) with mean period $\sim 500 \mathrm{sec}$ and $m \sim 3$ should be $\sim 15 \mathrm{~km} / \mathrm{sec}$, that is much slower than at low latitudes.

The phase velocity increases with increase of the period of the pulsations. For instance the apparent longitudinal phase velocity derived by Green (1976) for Pc3-4 pulsations ( $T \sim$ 20-60 sec) at geomagnetic latitude $\sim 54^{\circ}$ with $m \sim 10$ was about one order of magnitude higher than for $T \sim 500 \mathrm{~s}$ with $m \sim 3$ (Sodankyla-Lerwick).

Shinohara et al. (1998) while analyzing geomagnetic data from latitudinally dense network of stations in Brazilian sector have shown that the phases of $\mathrm{Pi} 2$ and $\mathrm{Pc} 4-5$ pulsations lag at the dip equator (obscure) than those at low latitudes during daytime. They have also shown that these lags will increase with increase in wave frequency. For some events of storm-time Pc5-6 events during daytime undertaken in this investigation, phase differences between KAK $\left(26.3^{\circ}\right)$ and GUA $\left(4.3^{\circ}\right)$ and between TAM $\left(25.1^{\circ}\right)$ and BNG $\left(4.5^{\circ}\right)$ are observed. The phases at TAM and KAK lag on an average, by nearly $40^{\circ}$ (one min. lag for $T \sim 8-9 \mathrm{~min}$ ) than those at $\mathrm{BNG}$ and GUA. However, during daytime, there were some simultaneous (with 1 min accuracy) events at KAK-GUA and TAM-BNG whereas no latitudinal phase differences at latitudinal range, $\sim 4-25^{\circ}$, were noticed during the nighttime.

Because the phase lags of equatorial pulsations are noticed only during the daytime, the phase lags must be related also to the high ionospheric conductivity. Shinohara et al. (1998) suggested a simple model to explain the phase lag of geomagnetic pulsations at dayside dip equator. This model includes the induction effect associated with the configuration of ionosphere-atmosphere-Earth layers.

The storm-time Pc5-6 pulsations at low latitudes and near the dip equator show separate packet structure of constant frequency with amplitude growing and decaying in time (Fig. 3). One can suspect that each individual wave packet was triggered by the same source like successions of solar wind impulses or disturbances perturbing the magnetopause. As a result, wave guide/cavity modes would be excited in the magnetosphere cavity formed between the magnetopause and turning point, where Alfvén waves are reflected with phase speeds matching the disturbance speed (e.g. Ruohoniemi $e t$ al., 1991; Harrold and Samson, 1992; Samson et al., 1992).

Some of the waves in the range of $2.5-3.0 \mathrm{mHz}$ recorded on February 21, 1994 (Fig. 4) were only observed near the dip equator (TRD) in the network of Indian stations. These pulsa- 
tions could probably be attributable to the generation/amplification of MHD waves by the equatorial electrojet instabilities. Saito (1983) has suggested the existence of nonmagnetospheric source of ULF disturbances at near equatorial latitudes. These fluctuations may be caused by the turbulence of equatorial atmosphere and ionosphere, incidence of compressional waves from the magnetosphere, acoustic impacts of earthquakes, tropical thunderstorms etc. Federov et al. (1999) have theoretically shown the possibility of ionospheric propagation of disturbances produced by variation of the electrojet currents. They have also shown the existence of large-scale compressional surface mode at small inclination of the geomagnetic field along the $E$ layer. The propagation of this mode, in the anisotropic ionospheric plasma, is called gyrotropic modes (Sorokin and Fedorovich, 1982), takes place in a diffusive way along the $E$ layer. Its damping scale is larger than the skin depth and may reach several kilometres. The apparent propagation velocity of these modes, according to them, is determined by height integrated Cowling conductivity at the near equatorial latitudes and by the combination of Hall and Pedersen conductivities at other latitudes, and is about $20-100 \mathrm{~km} / \mathrm{s}$ in Pc3-4 range. Rao (1996) has visualised a mechanism wherein intense instabilities (shears) of the daytime equatorial electrojet may excite wide-band MHD disturbances in the lower ionosphere and the part of these disturbances with frequencies corresponding to gyrotropic MHD modes (about 20-60 sec) are trapped into the $E$-layer and propagate away from the equator with velocities $10-30 \mathrm{~km} / \mathrm{s}$. In addition, Roy et al. (1999) have conjectured that the pulsations in the period ranges, 8 to 30 min, are produced by some local source in the daytime of the equatorial ionosphere populated by a variety of plasma irregularities in the form of density fluctuations. Perhaps, these pulsations observed by us at only the equatorial region are due to manifestation of gyrotropic MHD waves generated/amplified in the $E$-region of the equatorial electrojet.

Acknowledgments. This work was partly supported by Russian Foundation of Fundamental Research, grant RFFI \#98-05-64776. The Editor thanks J. J. Schott and A. Yoshikawa for their assistance in evaluating this paper.

\section{References}

Bolshakova, O. V., O. K. Borovkova, Yu. F. Borovkov, N. G. Kleimenova, and J. Bitterly, Magnetic storm on 13 March 1989: The structure of extremely disturbed magnetosphere obtained from geomagnetic pulsations Pc5, Geomagn. Aeron., 34, 492-500, 1995 (English translation).

Dunlop, I. S., F. W. Menk, H. J. Hansen, B. J. Fraser, and R. J. Morris, A multistation study of long period geomagnetic pulsations at cusp and boundary layers latitudes, J. Atmos. Terr. Phys., 56, 667-679, 1994.

Federov, E., V. Pilipenko, V. Surkov, D. R. K. Rao, and K. Yumoto, Ionospheric propagation of magnetohydrodynamic disturbances from the equatorial inosphere, J. Geophys. Res., 104, 4329-4336, 1999.

Green, C. A., The longitudinal phase variation of mid-latitude Pc3-4 micropulsations, Planet. Space Sci., 24, 79-85, 1976.

Harrold, B. G. and J. C. Samson, Standing ULF modes of the magnetosphere: a theory, Geophys. Res. Lett., 19, 1811-1814, 1992.

Herron, T. J., Phase characteristics of geomagnetic micropulsations, J. Geophys. Res., 71, 871-889, 1966.

Jain, A. R. and K. G. A. Srinivasacharya, Study of magnetic pulsations in the Indian equatorial region, J. Atmos. Terr. Phys., 37, 1477-1483, 1975.

Kikuchi, T., Evidence of transmission of the polar electric fields to the low latitude at time of geomagnetic sudden commencements, J. Geophys. Res., 91, 3101-3105, 1986.

Kikuchi, T. and T. Araki, Horizontal transmission of the polar electric field to the equator, J. Atmos. Terr. Phys., 41, 927-936, 1979.

Kitamura, T. I., O. Saka, M. Shimoizzumi, H. Tachihara, T. Oguti, T. Araki, N. Sato, M. Ishitsuka, O. Veliz, and J. B. Nyobe, Global mode of Pi2 waves in the equatorial regions - difference of Pi2 mode between high and equatorial latitudes, J. Geomag. Geoelectr., 40, 621-634, 1988.

Lilley, F. E. M. and D. J. Bennett, Micropulsations recorded by an array of magnetic variometers, J. Geophys. Res., 78, 1603-1607, 1973.

Liu, J. Y., Y. N. Huang, and F. T. Berkey, The phase relationship between ULF geomagnetic pulsations and HF Doppler frequency shift oscillations on March 24, 1991, J. Geomag. Geoelectr., 45, 109-114, 1993.

McHarg, M. G., J. V. Olson, and P. T. Newell, ULF cusp pulsations: diurnal variations and interplanetary magnetic field correlations with groundbased observations, J. Geophys. Res., 100, 19729-19742, 1995.

Olson, J. V. and G. Rostoker, Longitudinal phase variations of PC4-5 micropulsations, J. Geophys. Res., 83, 2481-2488, 1978.

Otnes, R. K. and L. Enochson, Applied Time Series Analysis, V.1 Basic Techniques, 449 pp., Wiley-Interscience, New York, 1978.

Rao, D. R. K., A result on Pc3-4 waves in the Indian equatorial region, $J$. Geomag. Geoelectr., 48, 1443-1449, 1996.

Reddy, C. A., S. Ravindran, K. S. Viswanathan, B. V. Krishna Murthy, D. R. K. Rao, and T. Araki, Observations of Pc5 micropulsation-related electric field oscillations in the equatorial ionosphere, Ann. Geophys., 12, 565-573, 1994.

Roy, M., D. R. K. Rao, B. M. Pathan, and R. L. Asinkar, Quiet time PS6 pulsation associated with equatorial electrojet irregularities, J. Atmos. Sol.-Terr. Phys., 1999 (in press).

Ruohoniemi, J. M., R. A. Greenwald, K. B. Baker, and J. C. Samson, HF radar observations of Pc5 field line resonances in the midnight/early morning MLT sector, J. Geophys. Res., 96, 15697-15710, 1991.

Saito, T., Resonance model on Pc3 sub-tropic region, in Contribuciones Cientificas para Conmemorar el 75 Aniversario del Observatorio del Ebro, pp. 175-180, 1983.

Saka, O., T. I. Kitamura, M. Shimoizzumi, T. Araki, T. Oguti, O. Veliz, and M. Ishitsuka, The effects of Non-Uniform Ionosphere on the Equatorial PC Pulsations, J. Geomag. Geoelectr., 40, 635-643, 1988.

Samson, J. C., B. G. Harrold, J. M. Ruohoniemi, R. A. Greenwald, and A. D. M. Walker, Field line resonances associated with MHD waveguides in the magnetosphere, Geophys. Res. Lett., 19, 441-444, 1992.

Sarma, S. V. S. and T. S. Sastry, On the equatorial electrojet influence on geomagnetic pulsation amplitudes, J. Atmos. Terr. Phys., 57, 749-754, 1995.

Sarma, S. V. S., T. S. Sastry, and Y. S. Sarma, On the latitudinal variation of magneto-telluric source field in the equatorial region of India, J. Geomag. Geoelectr., 43, 677-684, 1991

Sastry, T. S., Y. S. Sarma, and S. V. S. Sarma, Equatorial electrojet effects on geomagnetic pulsations, Ind. J. Radio Space Phys., 8, 249-253, 1979.

Sastry, T. S., Y. S. Sarma, and S. V. S. Sarma, Daytime Pi-pulsations in the equatorial region of India, J. Atmos. Terr. Phys., 45, 733-741, 1983.

Schott, J. J., N. G. Kleimenova, J. Bitterly, and O. V. Kozyreva, The strong Pc5 geomagnetic pulsations in the initial phase of the great magnetic storm of March 24, 1991, Earth Planets Space, 50, 101-106, 1998.

Shinohara, M., K. Yumoto, N. Hosen, A. Yoshikawa, H. Tachihara, O Saka, T. I. Kitamura, N. B. Trivedi, J. M. Da Costa, and N. J. Schuch, Wave characteristics of geomagnetic pulsations across the dip equator, $J$. Geophys. Res., 103, 11745-11754, 1998.

Sorokin, V. and G. V. Fedorovich, Propagation of short period waves in the ionosphere, Izv. VUZov (Radiofizika), 25, 495-507, 1982.

Trivedi, N. B., B. R. Arora, A. L. Padilha, J. M. Da Costa, S. L. Dutra, F. H. Chamalaun, and A. Rigoti, Global Pc5 geomagnetic pulsations of March 24, 1991, as observed along the American sector, Geophys. Res. Lett., 24, 1683-1686, 1997.

Walker, A. D. M., J. M. Ruohononiemi, K. B. Baker, R. A. Greenwald, and J. C. Samson, Spatial and temporal behavior of ULF pulsations observed by Goose bay HF radar, J. Geophys. Res., 97, 12187-12202, 1992.

Ziesolleck, C. W. S. and F. H. A. Chamalaun, A two dimensional array study of low-latitude Pc5 geomagnetic pulsations, J. Geophys. Res., 98, 13705-13713, 1993.

Ziesolleck, C. W. S. and D. R. McDiarmid, Auroral latitude Pc5 field line resonances: Quantized frequencies, spatial characteristics and diurnal variation, J. Geophys. Res., 99, 5817-5830, 1994.

B. M. Pathan (e-mail: bmpathan@iig.iigm.res.in), N. G. Kleimenova, O. V. Kozyreva, D. R. K. Rao, and R. L. Asinkar 